\title{
Reward and attitudes: The unintended outcomes of an effective performance appraisal
}

\begin{tabular}{|c|c|}
\hline $\begin{array}{l}\text { Authors: } \\
\text { Solomon M. S } \\
\text { Katende }^{1} \\
\text { Erik D. Schmik } \\
\text { Theuns G. Pel }\end{array}$ & $\begin{array}{l}\text { emakula- } \\
\text { I }^{2}\end{array}$ \\
\hline \multicolumn{2}{|c|}{$\begin{array}{l}\text { Affiliations: } \\
{ }^{1} \text { Graduate School of Business } \\
\text { and Government Leadership, } \\
\text { North-West University, } \\
\text { Mafikeng, South Africa }\end{array}$} \\
\hline \multicolumn{2}{|c|}{$\begin{array}{l}{ }^{2} \text { Cranefield College, Pretoria, } \\
\text { South Africa }\end{array}$} \\
\hline \multicolumn{2}{|c|}{$\begin{array}{l}\text { Correspondence to: } \\
\text { Theuns Pelser }\end{array}$} \\
\hline \multicolumn{2}{|c|}{$\begin{array}{l}\text { Email: } \\
\text { theuns.pelser@nwu.ac.za }\end{array}$} \\
\hline \multicolumn{2}{|c|}{$\begin{array}{l}\text { Postal address: } \\
\text { Private Bag X2046, } \\
\text { Mmabatho 2745, } \\
\text { South Africa }\end{array}$} \\
\hline \multicolumn{2}{|c|}{$\begin{array}{l}\text { Received: } 27 \text { Mar. } 2013 \\
\text { Accepted: } 27 \text { June } 2013 \\
\text { Published: } 09 \text { Oct. } 2013\end{array}$} \\
\hline \multicolumn{2}{|c|}{$\begin{array}{l}\text { How to cite this article: } \\
\text { Semakula-Katende, S.M., } \\
\text { Schmikl, E.D., \& Pelser, } \\
\text { T.G. (2013). Reward and } \\
\text { attitudes: The unintended } \\
\text { outcomes of an effective } \\
\text { performance appraisal. SA } \\
\text { Journal of Human Resource } \\
\text { Management/SA Tydksrif vir } \\
\text { Menslikehulpbronbestuur } \\
\text { 11(1), Art. \#545, } 11 \text { pages. } \\
\text { http://dx.doi.org/10.4102/ } \\
\text { sajhrm.v11i1.545 }\end{array}$} \\
\hline \multicolumn{2}{|c|}{$\begin{array}{l}\text { Copyright: } \\
\text { (C) 2013. The Authors. } \\
\text { Licensee: AOSIS } \\
\text { OpenJournals. This worl } \\
\text { is licensed under the } \\
\text { Creative Commons } \\
\text { Attribution License. }\end{array}$} \\
\hline \multicolumn{2}{|l|}{ Read online: } \\
\hline 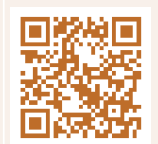 & $\begin{array}{l}\text { Scan this QR } \\
\text { code with your } \\
\text { smart phone or } \\
\text { mobile device } \\
\text { to read online. }\end{array}$ \\
\hline
\end{tabular}

Orientation: Focus was on the role of reward and attitudes as major determinants in enhancing the effectiveness of performance appraisal systems.

Research purpose: To develop a structural model from the qualitative and quantitative findings from which to address the identified gaps in order to improve the effectiveness of appraisals.

Motivation for the study: The attention that role players tended to give to the rewarding of employees during the appraisal process made it appear as the only important determinant of an appraisal's success. In appraisals in many public institutions, reward has been given unnecessary prominence over other drivers, such as management and development. That led most key role players (leaders, managers and employees) to perceive the current employee performance management and development system (EPMDS) to be purely for monetary (salary increments and cash bonuses) and non-monetary (promotion) purposes, which, in turn, compromised its effectiveness.

Research design, approach and method: Structural equation modelling (SEM) was utilised as a statistical technique for testing and estimating causal relations using a combination of statistical data and qualitative causal assumptions. This allowed both confirmatory and exploratory modelling to be undertaken, which is suited to both theory testing and theory development. A triangulation of quantitative (questionnaire) and qualitative (interview) study was conducted. A total of 300 questionnaires were distributed to nine government hospitals in the Free State province, namely Mofumahadi Manapo Mopeli, Dihlabeng, and Boitumelo regional hospitals, as well as Elizabeth Ross, Thebe, Phekolong, Mpumelelo, Reitz and Ficksburg district hospitals. There was a high response rate of 96 per cent, a total of 287 completed questionnaires. Respondents ranged from top executives, middle management, line management, to employees of all categories.

Main findings: Reward and attitudes were found to the unintended outcomes of an effective performance appraisal.

Practical/managerial implications: Remunerative rewards should be part of a holistic appraisal approach and not simply a one-sided approach.

Contribution/value-add: This article addressed the void or the wrong perception regarding the role of reward and attitudes in appraisals, and established that they were outcomes, and not determinants, of appraisal effectiveness.

\section{Introduction \\ Problem statement}

This study presents the evidence of a research effort exposing the performance management experience in public government hospitals, which by implication reflects recent issues in the South African public service. In many organisations, including public institutions, performance appraisal systems remain some of the great paradoxes of effective human resource management, according to Rudman (2004).

Countries in the developing world, including South Africa, have made strides in advancing corporate administrative systems to improve the performance of employees in the public service (Sangweni, 2003). Performance appraisals provide valuable performance information to a number of critical human resource activities, such as the allocation of rewards - merit pay, promotions - feedback on development, assessment of training needs, evaluation of other human resource systems, such as selection predictors, and performance documentation for legal purposes (Cleveland, Murphy \& Williams, 1989). 


\section{The key focus of the study}

This study addresses the key factors that influence performance appraisal in achieving its intended purpose. Specifically, the focus is on the role of reward and attitudes in the success of appraisals in public government hospitals. Performance appraisals offer much potential for enhancing organisational effectiveness through human resource decisions. They can also help to improve and satisfy the needs of employees for performance and feedback (Fisher, Schoenfeldt \& Shaw, 2003; Fletcher, 1993; Fletcher \& Jones, 1993; Goodge, 2005; Ilgen, Fisher \& Taylor, 1979; Pfeffer \& Veiga, 1999).

\section{Background of the study}

Performance appraisal is an organisational system comprising deliberate processes for determining how to improve staff effectiveness, according to Winston and Creamer (1997). There is evidence that the entire subject of performance appraisal remains a practical challenge to the academics who designed it, to researchers, and to the leaders, managers and practitioners who use it (Freeman, 2002). This is, in part, owing to the role ambiguity of the key role players, which necessitates identification and clarification of the roles of the different players from the onset, specifically those of leaders, managers and employees. This would ensure that ambiguity of roles is eliminated and teamwork and active participation are encouraged, which will influence attitudes, motivation and expectations of employees; this is necessary for the successful administration of reward (SemakulaKatende, 2012).

Performance assessment and management performance are crucial links in the human resource management (HRM) process (Hutchinson \& Purcell, 2003); they are the functions that organisations use in order to assess their employees' performance on all levels and determine appropriate rewards or remedial actions. The role of HRM in performance appraisal and management was mainly one of working with line managers to establish performance standards, the performance dimensions to be measured, as well as the appraisal procedures to ensure accuracy of the outcomes.

\section{Research purpose}

In this study, the authors, however, argued that if reward was a determinant, it should have been considered alongside other key determinants, notably leadership succession, employee development and productivity, and management competency. These should be treated in the same manner as other outcomes, such as productivity, development and sustained performance, since they are not in fact determinants as they were earlier thought to be.

\section{Objective of the study}

The objective of the study was to establish why the employee performance management and development system (EPMDS) was largely ineffective in achieving its intended objectives and to identify the factors influencing its implementation.
The objective of the EPMDS was then to provide a corporate framework to manage and secure effective and efficient organisational performance in meeting internal and external customer needs and expectations. It was aimed at optimising individual excellence and achievement, in order to contribute to the overall achievement of the organisational goals to improve service delivery (Free State Provincial Government, 2003, 2007).

The EPMDS as a policy was applicable to all jobholders on salary levels 1-12, who were appointed in terms of the Public Service Act (Republic of South Africa, 1994) (as amended) within the Free State Provincial Government (FSPG) on permanent and contracted appointments. This instrument was also designed to make informed decisions regarding probations, rewards (pay progression and cash bonuses) and skills development of jobholders.

\section{Literature review}

Performance appraisals are widely used in HRM and are also the subject of extensive critique. Despite their drawbacks, performance appraisal systems seem to offer so much potential for employees' performance, feedback and reward, which are central to HRM decisions. The prominence of reward in the appraisal process remains a challenge that this study hoped to address.

\section{Trends from research literature}

The cost of implementing appraisals has been escalating at a rate organisations are finding they are unable to match. Organisations are forced to embrace innovative reengineering by making service less cumbersome through the introduction of a legislative framework that curtails costs.

Banks and Murphy (1985) reiterate that organisations continue to express disappointment in performance appraisal systems, despite advances in appraisal technology and the new tools being developed (Kaplan \& Norton, 2005; Neely, Adams \& Kennerley, 2002; Ulrich, 1997; Ulrich, Smallwood \& Sweetman, 2008).

There have been previous studies done in the public health sector locally (Blanche, Durrheim and Painter, 2006; Bless \& Higson-Smith, 2000; Cameron \& Stone, 2007), specifically focusing on performance appraisal, but they treated employee attitudes and reward as one of the key drivers of the system.

\section{Definitions}

By definition, performance appraisal (PA) is a formal system of measuring, evaluating and influencing the jobrelated attributes, behaviours and outcomes of an employee (Rudman, 2004). PA aims to determine how productive an employee is and whether the productivity of the employee can be improved (Renton, 2000).

Performance appraisal, also known as employee appraisal, is that portion of a performance assessment in which the 
contribution of the employee to the goal attainment of the organisation during a specified period of time is assessed. This is usually evaluated in terms of quality, cost and time, according to Hutchinson and Purcell (2003). Performance feedback (PF), informs employees about how well they have performed in comparison with the standards of the organisation (Hill \& Jones, 2001) and what is expected from them. Without a structured appraisal system, there is little chance of ensuring that the judgments made are lawful, fair, defensible and accurate (Karl \& Wexley, 1989).

Margulies (2004) maintains that performance appraisal systems begin as simple methods of income justification. Thus, appraisal is used to decide whether the salary or wage of an individual employee is justified. The process is firmly linked to material outcomes (Fisher et al., 2003): if the performance of an employee is found to be less than ideal, a cut in pay or demotion follows. On the other hand, if the employee's performance is seen to be better than the supervisor expected, a pay rise or promotion is given. Little consideration, if any, is given to the developmental component of appraisal (Wolff, 2005).

\section{The EPMDS}

The EPMDS is an appraisal system of the FSPG HRM (FSPG, 2003, 2007), introduced in 2003. It was developed by the Department of Public Service and Administration (DPSA) as a framework for voluntary use by national and provincial departments (FSPG, 2003), with the choice of implementation on a permanent basis. The EPMDS was aimed at improving performance by directing attention to the key areas of activity, which were identified through strategic planning processes. That established clear links amongst organisational development and culture change, the delivery of quality services and the personal and professional development of jobholders at work.

The instrument was also designed to allow for informed decisions regarding probations, rewards (pay progression and cash bonuses), and skills development of jobholders. The policy viewed performance on an individual level and linked it to the performance of both the service unit and the organisation in a performance and development management cycle over a one-year period (FSPG, 2007). Its introduction presented specific challenges to every manager throughout the organisation to create a working environment in which jobholders were developed and motivated to deliver the best performance possible (Saunders, Lewis \& Thornhill, 2007).

The EPMDS, as a framework for voluntary use by national and provincial departments, was aimed at planning, managing and improving employee performance, and managing administration of rewards (FSPG, 2003, 2007). Almost a decade after its inception, the EPMDS appears to have been ineffective in meeting these objectives. In addition, within the EPMDS assessment there is still some uncertainty regarding the implementation phase. For instance, the allocation of scores over $150 \%$ instead of $100 \%$ and the guiding of supervisors on making the correct score allocations are still not clear (FSPG, 2007).

Leaders and managers are also not well prepared for the responsibility of ensuring that the specific operational plans are available and are in line with the departmental objectives. The EPMDS linked organisational goals into employees' attitudes and expectations to ensure that the plans for rewarding and personal development were developed simultaneously. Reward, however, appears to have been given more attention (McEvoy, 1990). This has impeded the effectiveness of the EPMDS in the attainment of organisational goals and performance appraisal, as is stipulated in the FSPG HRM Business Plan (FSPG, 2008). In this study, it is argued that other factors and constructs have the potential to influence the successful, sustained use of employee performance appraisals.

\section{Determinants and outcomes of performance appraisals}

The objective of this study was to establish the gap in the existing literature surrounding the successful, sustained application of a performance appraisal system in addressing the prominence of reward in performance appraisals. This entailed identifying the major determinants or drivers and the outcomes expected of an effective appraisal. Twenty factors were identified as drivers of performance appraisal.

These were reduced to 12 by factor analysis: (1) leadership process, (2) organisational culture and climate, (3) human motivation, (4) selection and placement of talent, (5) communication, (6) conducting and managing appraisals, (7) management of expectations, (8) resources, (9) responsibility and accountability, (10) reward, (11) attitudes and (12) managing diversity in the workplace (Semakula-Katende, 2012).

Addressing these factors was envisaged to make the current ineffective EPMDS work successfully to enhance organisational effectiveness within the Department of Health in South Africa. In addition, this study tries to explore the extent to which those determinants, specifically rewards and attitudes, predicted different dimensions of the current effectiveness of the employee performance (Gillen, 2007). This was necessary for the organisation to attain intended outcomes (goals and objectives), namely leadership succession, teamwork, employee development and empowerment and effective communication.

The EPMDS was grossly misunderstood and incorrectly implemented. Consequently, the EPMDS implementation was not smooth sailing. The EPMDS had many hitches, bearing in mind that different categories of stakeholders had a variety of skills, expectations, experiences and motives (Davis, 2001). Employees, like leaders and managers, have varied expectations that they hope to be met during appraisal (Davis, 2001). For some, reward is central to the effectiveness of appraisals, whilst for others, it is the opportunity to have a tangible say in workplace affairs, such as employee appraisal, 
motivation, training and development (Forsyth, 2004). For the unions of workers, employers, and other stakeholders, different expectations were anticipated which resulted in numerous conflicts of interest.

\section{Appraisal effectiveness for organisational success}

According to Boyatzis (1982), effective performance occurs when the critical components (job demands, individual competencies and organisational environment) of his model are consistent. Quinn (1988) and Quinn, Faerman, Thompson and McGrath (1996) differ; they argue that the contributions of managers determine organisational effectiveness, thereby supporting the proposition that the different perspectives of the roles of managers are actually closely related. Hutchinson and Purcell (2003) support these views.

Quinn's (1988) competing values framework accounts for the non-routine cognitive complexity associated with all managerial jobs; it perceives organisations as social structures that are created to continuously support the collaborative pursuit of specific goals. In Semakula-Katende's (2012) research study, the empirical evidence confirms that appraisal effectiveness is influenced by the competency of key individual role players. In view of the perception that role players have about performance appraisal, an analysis of empirical evidence with regard to their experience in the use of performance appraisals in South Africa was undertaken, so as to enhance in leaders, managers and employees a greater understanding of what truly constitutes an effective performance appraisal and how it really works.

Key determinants were identified and aligned with the role players, in order to enhance organisational effectiveness. Links were provided between organisational effectiveness and successful employee performance appraisals, which were then investigated in terms of the task and contextual performance of employees. An attempt was made to organise the concepts, constructs, dimensions and measures into partially integrated links for an effective appraisal system. The complete final integration, however, was presented in the doctoral study after the major determinants had been identified. Thus, the integration and alignment of those factors were completed only after the literature review to ensure firm grounds on which to build a normative model.

That model ought to benchmark any empirical analysis to examine the degree of good-fit or mismatch. The mismatch or poor-fit between the normative model and the empirical research findings that emerged from the research led to the opportunity to develop a new modified performance evaluation model which it is hoped will lead to strategies for overcoming the shortcomings of its predecessors (SemakulaKatende, 2012; David \& Sutton, 2004).

\section{Employee commitment in appraisal effectiveness}

Employee commitment is inseparable from a successful HRM activity such as performance appraisal, as evidenced in Semakula-Katende's (2012) research study. In that study, development was established as the construct responsible for discovering and developing employee potential, and selecting and placing talent for effective utilisation. This was in line with Tucker, McCarthy and Benton (2002) and Kaplan and Norton (2005), who distinguished development as another key construct or component of successful performance appraisals; they argue that the outcome goals of appraisals ought to be objective, quantifiable and measurable.

This view concurs with Kaplan and Norton's (2005) fourperspective balanced scorecard, in which they specifically emphasise employee initiatives and the learning component in order to enhance the effectiveness of the appraisal system. This, in turn, augments the representativeness of the normative model, in order to improve the overall success of the organisation (Wolff, 2005). The development of the new model was meant to ensure that the elements and standards missing in the EPMDS were incorporated, including the performance plan, in order to comply with regulatory requirements of the Department of Health (FSPG, 2008).

Firstly, the aim was to measure some kind of productivity and to motivate employees to work harder (Cropanzano \& Wright, 2001). Next was to link this to both the needs of employees and organisational effectiveness, as well as with people having to achieve targets around performance measures (goals or objectives or key performance areas). This gave rise to systems thinking and the development and attempt to create integrated organisational and management performance or employee performance appraisal systems (Boyatzis, 1982; Quinn, 1988).

\section{Method}

\section{Research approach}

This study used triangulation to overcome the potential bias and sterility of a single-method approach (Collis \& Hussey, 2009). Saunders et al. (2007) argue that data ought to be collected through methods such as self-administered questionnaires and personal interviews. These were the methods employed in this study to collect data from a sample of employees of eastern Free State public institutions. A triangulation of data collection via scheduled collection, a methodology of quantitative and qualitative approaches, and interdisciplinary theories were employed (EasterbySmith, Thorpe \& Lowe, 1994).

Structural equation modelling (SEM) was utilised as a statistical technique for testing and estimating causal relations using a combination of statistical data and qualitative causal assumptions. This allowed both confirmatory and exploratory modelling to be undertaken, which is suited to both theory testing and theory development. The research method was primarily quantitative in nature with statistical analysis of data collected by survey questionnaires, which provided for the collection of large amounts of data. This was supplemented with a qualitative technique, interviews conducted with 65 of the respondents, to enhance the quality of data collection and to validate the data. That option was 
necessary because there was limited secondary data on the identity and effects of the determinants of the effectiveness of performance appraisals, specifically the EPMDS, in order to gain insights into the appraisal dilemma.

A questionnaire was used, and was complimented by qualitative personal interviews with a selected number of employees, as advocated by Winberg (1997). Consequently, triangulation ensured that the quantitative approach compensated for the weakness found in the qualitative methods, and vice versa (Amaratunga, Baldry, Sarshar \& Newton, 2002). Due to the aforementioned, only a representative sample was taken for use in the study.

\section{Research method}

\section{Research method rationale}

The method of data triangulation was employed in the research study to overcome the potential bias and sterility of a single-method approach. Methodological triangulation culminates in the diverse collection of data from different sources using various techniques such as questionnaires and interviews, or surveys and field studies, which can then be juxtaposed to analyse data in a credible manner (EasterbySmith et al., 1994).

\section{Research participants and sampling}

This study employed both probability (random) and nonprobability (purposive-judgemental) sampling procedures to enhance data collection and interpretation (Blanche et al., 2006; Cooper \& Schindler, 2008; West, Arnold, Corbett \& Fletcher, 1992). This was necessary to ensure efficiency, because some of questionnaires and interviews were conducted simultaneously. Purposive sampling was used to improve data collection because it was based on the judgement and skills of the researcher, in line with the argument of Bless and Higson-Smith (2000). Purposive sampling was also used to select the leaders, managers, and employees who participated in the personal interviews.

A total of 300 questionnaires were distributed to nine sampled government hospitals in South Africa. There was a high response rate of $96 \%$, a total of 287 completed questionnaires (see Table 1).

The hospitals participating in this study had been using the EPMDS since its inception in 2003, as recommended by Carroll and Hannah (2000). They were, therefore, conversant with the problems associated with the system. The high response rate may be attributed to the level of enthusiasm the participants had, their desire to have something to say about the ineffective process, and the data collection methods that afforded every respondent optimal privacy and anonymity. Similarly, responses from the 15-minute interviews were immediately dispatched together with the questionnaire.

\section{Measuring instrument}

Data was collected through the methods of a self-administered questionnaire and personal interviews on a sample of employees of the eastern Free State public health institutions. See Table 2 for the technical details of the empirical research.

\section{Research procedure}

Formal protocol in the Free State provincial health industry was observed. Permission to conduct the study was granted by the Head of Health and the nine participating CEOs and executive committees. Several preparatory visits were made to set the schedule and venue for the questionnaires and interviews. This was followed by email and telephonic contacts to plan and schedule the survey (questionnaire and interview) appropriately and conveniently.

Three hundred questionnaires (see Table 3) were administered in proportion to the level of service or employment as follows: $30 \%$ to the district and $70 \%$ to the regional hospitals. There were three regional hospitals and seven district ones,

TABLE 1: Response rate for the survey.

\begin{tabular}{ll}
\hline Response & Total \\
\hline Distributed questionnaires & 300 \\
Returned questionnaires & 287 \\
Response rate & $96 \%$ \\
Unusable questionnaires & 3 \\
Usable questionnaires & 284 \\
\hline
\end{tabular}

TABLE 2: Technical details of the empirical research.

\begin{tabular}{ll}
\hline Research population categories & $\mathbf{2 4 0 0}$ government healthcare employees \\
\hline Distribution 1: District & 924 \\
Distribution 1: Regional & 1476 \\
Sample size & 300 \\
Distribution 2: District & 90 \\
Distribution 2: Regional & 210 \\
Sample error & $0.05 \%$ \\
Confidence level & $95.00 \%$ \\
Sample selection & $\begin{array}{l}\text { Probability stratified proportionate and } \\
\text { disproportionate }\end{array}$ \\
Data collection method & $\begin{array}{l}\text { Questionnaire personally delivered to identified } \\
\text { potential participants in different public hospitals } \\
\text { as well as personal interviews conducted }\end{array}$ \\
Data collection period & March 2009-April 2009 \\
\hline
\end{tabular}

TABLE 3: Distribution according to number of employees.

\begin{tabular}{lll}
\hline Level of distribution & Number of employees & $\%$ \\
\hline Level of hospital A & 1148 & 48 \\
District or level 1 & 1252 & 52 \\
Regional or level 2 & $\mathbf{2 4 0 0}$ & 100 \\
Total & & \\
Level of hospital B & 7 & 70 \\
District or level 1 & 3 & 30 \\
Regional or level 2 & 10 & 100 \\
Total & & \\
Level of hospital C & 90 & 30 \\
District or level 1 & 210 & 70 \\
Regional or level 2 & $\mathbf{3 0 0}$ & 100 \\
Total & & \\
Level of management & 13 & 11 \\
Top executive & 33 & 85 \\
Middle or operational managers & & 100 \\
(Cost centre managers) & 254 & \\
Employees & $\mathbf{3 0 0}$ & \\
Total & &
\end{tabular}


a total of nine participating hospitals. Ten interviews were conducted for each of regional hospitals and five for each district hospitals; these lasted $15 \mathrm{~min}$ each. The questions for the questionnaire and interviews were formulated to address the objectives of the study. The questionnaires and interviews were conducted on the same day for each hospital to facilitate data collection and limit disruption to service.

Voluntary participation and the strict observation of ethical guidelines (such as anonymity, privacy and confidentiality) were ensured. A request was made to administer questionnaires in single sittings to reduce the survey time and the disruption of services. In each participating hospital, it was required that one hour was set aside for the questionnaires in one sitting. Fifteen minutes were needed for each of the 65 interview nominees from the nine participating hospitals. A total of 300 questionnaires and 65 interviews were conducted.

In this study, caution and some degree of common sense were exercised so as not to undermine the rights to privacy, confidentiality and anonymity of participants. Participation in the study by employees - managers and workers - was purely voluntary. Participating institutions and employees were required to agree, without coercion, to take part in the study, some on the condition that they remained anonymous in published materials from the study. They were made aware of the sensitive nature of the study. The researcher's desire for additional data was balanced by the interests of participating leadership, management, employees and organisations.

In this study, data was collected from individual human beings, employees of the South African government department. Prior approval was obtained from relevant committees and officials in accordance with the NorthWest University Ethics Committee guidelines (NorthWest University, 2007). This was critical in determining compliance with academic and ethical considerations in terms of structural equation modelling, validity, reliability and dimensionality. Participants were informed about their right to withdraw their participation at any time without providing reasons and that such a decision would be honoured. Furthermore, it was explained to participants that no benefits of any sort were expected besides sharing in the findings and recommendations.

\section{Statistical analysis}

In this study, analysis of data was undertaken using the Statistical Package for the Social Sciences (SPSS), version 10.1, and structural equation modelling (SEM) using Microsoft Windows EQS 6.1, as recommended by other scholars (Bentler, 1995; Blanche et al., 2006; Byrne, 2001; Collis \& Hussey, 2009).

These were employed to compare and contrast the hypothesised relationships in the structural model and to verify the construct validity of the scales employed. The research findings were organised and presented in tabular form. Table 3 reflects the descriptive statistics of the moderation construct (demographic variables), specifically the frequency and percentages. These entailed analysing statistics of the level of responsibility, the service level, gender, age, race, education and experience, in terms of the mean, standard deviation, variance and skewness, as displayed in the table. They, however, exhibited no statistical significance, besides the high response rate, to augment the results, as shown in Table 4. Some subsamples had lowest mean values, gender (1.69) and responsibility level (1.35), supporting the fact that challenges of the EPMDS equally affected both sexes and both management and employees.

The empirical findings of this study in terms of moderation impact on appraisal effectiveness were indifferent; however, findings from qualitative data (interviews) appear to suggest indirect impact through leadership, management and communication.

Table 5 and Table 6 capture the correlations among the 12 determinants in terms of range, means, minimums, maximums and variances for the leadership, administration, development, information and management competency subsamples of the sample $(n=291)$. Table 5 reveals no statistical significance.

The discrepancy between the subsamples in the five themes may be attributed to the perception the employees had about these factors in relation to the EPMDS process. Generally, the respondents in the sample strongly agreed that leadership $\left(\mathrm{V}_{1}\right.$ - mean $\left.=16.45\right)$, organisational $/$ performance culture and climate $\left(\mathrm{V}_{2}-\right.$ mean $\left.=12.91\right)$, communication $\left(\mathrm{V}_{5}-\right.$ mean $\left.=8.51\right)$ and rewards $\left(\mathrm{V}_{10}\right.$ - mean $\left.=10.20\right)$ had as much impact on the effectiveness of appraisals as training managers to manage

TABLE 4: Descriptive statistics of demographics of the EPMDS effectiveness

\begin{tabular}{|c|c|c|c|c|c|c|}
\hline \multirow[t]{2}{*}{ Descriptor } & \multicolumn{4}{|c|}{ Statistic } & \multicolumn{2}{|c|}{ Skewness } \\
\hline & $N$ & Mean & Standard deviation & Variance & Statistic & Standard error \\
\hline Department & 292 & 1.00 & 0.000 & 0.000 & 0.0 & 0.0 \\
\hline Hospital levels & 292 & 1.77 & 0.419 & 0.176 & -1.317 & 0.143 \\
\hline Gender & 292 & 1.69 & 0.463 & 0.214 & -0.835 & 0.143 \\
\hline Responsibility level & 292 & 1.35 & 0.519 & 0.269 & 1.224 & 0.143 \\
\hline Race & 292 & 3.35 & 1.009 & 1.017 & -1.181 & 0.143 \\
\hline Age interval & 292 & 2.77 & 0.760 & 0.578 & -0.243 & 0.143 \\
\hline Education level & 292 & 2.72 & 1.077 & 1.159 & 0.303 & 0.143 \\
\hline Experience level & 292 & 3.04 & 1.135 & 1.287 & 0.125 & 0.143 \\
\hline Valid $n$ (list wise) & 292 & - & - & - & - & - \\
\hline
\end{tabular}


TABLE 5: Descriptive statistics of determinants of the EPMDS effectiveness.

\begin{tabular}{|c|c|c|c|c|c|c|}
\hline Variables & $N$ & Minimum & Maximum & Mean & Variance & Standard deviation \\
\hline$V_{1}-$ Leadership process & 187 & 8.000 & 32.000 & 16.43 & 22.683 & 4.763 \\
\hline $\mathrm{V}_{2}-$ Performance culture and climate & 187 & 6.000 & 24.000 & 10.41 & 12.587 & 3.538 \\
\hline $\mathrm{V}_{4}-$ Selection and placement of talents & 187 & 4.000 & 16.000 & 7.331 & - & - \\
\hline $\mathrm{V}_{5}-$ Communication and MIS & 187 & 5.000 & 20.000 & 8.505 & 10.899 & 3.301 \\
\hline $\mathrm{V}_{6}-$ Training to manage appraisals & 187 & 3.000 & 12.000 & 6.254 & 6.794 & 2.607 \\
\hline$V_{7}-$ Expectations & 187 & 5.000 & 20.000 & 15.75 & 6.794 & 2.607 \\
\hline$V_{8}-$ Resources & 187 & 6.000 & 24.000 & 10.91 & 6.794 & 2.607 \\
\hline $\mathrm{V}_{10}-$ Reward & 187 & 4.000 & 16.000 & 7.902 & 11.055 & 3.325 \\
\hline $\mathrm{V}_{11}$-Attitudes & 187 & 7.000 & 28.000 & 14.05 & - & - \\
\hline
\end{tabular}

TABLE 6: Descriptive statistics of key determinants of the EPMDS.

\begin{tabular}{|c|c|c|c|c|c|c|c|}
\hline \multirow[t]{2}{*}{ Key determinants } & \multirow[t]{2}{*}{ Variables } & \multicolumn{4}{|c|}{ Statistic } & \multicolumn{2}{|c|}{ Skewness } \\
\hline & & $N$ & Mean & Standard deviation & Variance & Statistic & Standard error \\
\hline \multirow[t]{2}{*}{ Theme 1: Leadership construct } & $V_{1}-$ Leadership process & 292 & 2.06 & 0.927 & 0.764 & 0.535 & 0.143 \\
\hline & $\mathrm{V}_{2}$ - Culture or climate & 292 & 1.84 & 0.810 & 0.663 & 0.767 & 0.143 \\
\hline \multirow{2}{*}{$\begin{array}{l}\text { Theme 2: Administration } \\
\text { construct }\end{array}$} & $\mathrm{V}_{8}-$ Managing resources & 292 & 1.82 & 0.777 & 0.607 & 0.790 & 0.143 \\
\hline & $V_{9}$-Accountability or responsibility & 292 & 1.81 & 0.870 & 0.763 & 0.811 & 0.143 \\
\hline $\begin{array}{l}\text { Theme 3: Development } \\
\text { construct }\end{array}$ & $\begin{array}{l}\mathrm{V}_{4}-\text { Development or placement of } \\
\text { potential or talent }\end{array}$ & 292 & 1.92 & 0.862 & 0.751 & 0.688 & 0.143 \\
\hline Theme 4: Information construct & $\mathrm{V}_{5}-$ Communication & 292 & 1.70 & 0.831 & 0.693 & 1.043 & 0.143 \\
\hline \multirow{2}{*}{$\begin{array}{l}\text { Theme 5: Management } \\
\text { competency construct }\end{array}$} & $\mathrm{V}_{6}-$ Training or appraisals & 292 & 2.15 & 0.913 & 0.835 & 0.404 & 0.143 \\
\hline & $\mathrm{V}_{12}$ - Diversity & 292 & 3.10 & 0.852 & 0.740 & 0.410 & 0.143 \\
\hline \multirow{2}{*}{$\begin{array}{l}\text { Theme 6: Moderation } \\
\text { construct }\end{array}$} & $V_{3}-$ Motivation & 292 & 2.68 & 1.063 & 1.130 & -0.259 & 0.143 \\
\hline & $\mathrm{V}_{7}-$ Expectations & 292 & 3.10 & 0.78 & 0.770 & 0.684 & 0.143 \\
\hline \multirow[t]{2}{*}{ Appraisal outcomes } & $\mathrm{V}_{10}-$ Managing reward & 292 & 2.04 & 0.992 & 0.993 & 0.564 & 0.143 \\
\hline & $\mathrm{V}_{11}$ - Attitudes & 292 & 2.00 & 0.800 & 0.820 & 0.630 & 0.143 \\
\hline
\end{tabular}

TABLE 7: Model fit measures' indicators.

\begin{tabular}{lll}
\hline Fit measures & Fit measures' indicators & Interpretation \\
\hline Chi-square $\left({ }^{2}\right.$ ) & $<0.50$ & - \\
& $>0.50$ & Acceptable fit \\
Root mean square residual & 0.00 & Exact fit \\
(RMSEA) & $\leq 0.05$ & Close fit \\
& $\leq 0.08$ & Reasonable \\
& $>0.10$ & Over fit \\
Standard root mean residual & $<0.50$ & Exact fit \\
(SRMR) & $>0.50$ & Over fit \\
Comparative fit index (CFI) & $0.00-1.00$ & Fit \\
& Close to 1 & Perfect fit \\
& $>1.00$ & Over fit \\
Normalised fit index (NFI) & $0.00-1.00$ & Fit \\
& Close to 1 & Perfect fit \\
& $>1.00$ & Over fit \\
Goodness-of-fit index (GFI) & $0.00-1.00$ & Fit \\
& Close to 1 & Perfect fit \\
& $>1.00$ & Over fit \\
Adjusted goodness-of-fit index & $0.00-1.00$ & Fit \\
(AGFI) & Close to 1 & Perfect fit \\
& $>1.00$ & Over fit \\
\hline & & \\
& & \\
& &
\end{tabular}

appraisals $\left(\mathrm{V}_{6}-\right.$ mean $\left.=8.59\right)$, expectations $\left(\mathrm{V}_{7}-\right.$ mean $\left.=8.59\right)$ and resources $\left(\mathrm{V}_{8}-\right.$ mean $\left.=8.59\right)$.

The research findings support leadership, communication and management as key determinants of the effectiveness of appraisals, whilst there was less support for moderation, despite the employee perception emanating from the interview results.
Table 6 displays the means, standard deviations, variances and skewness of the determinants, the lack of major differences in which suggests that those variables were appropriately placed and addressed the purpose as intended. Similar sampling has been maintained, although employees involved in this study were demographically diverse in a number of ways, namely level of management, location, age, gender, race, education and experience.

This analysis assisted in establishing the generalisability of the measurement instrument and contributed to the existing empirical base of what constitutes an effective employee performance appraisal system.

\section{Results}

The results in this study have been generated by means of descriptive and inferential statistics. Descriptive statistics were applied to determine the summated mean scores, which related to the various stages of the development of the model. Inferential statistics used in this study are illustrated in Table 7, Table 8 and Table 9. SEM techniques were applied to the data to obtain various factor analyses and third generation model and fit indices as examined already. Table 7 displays the model fit measure indicators.

Table 8 displays some empirical results of the study.

Table 9 depicts the measures that were found appropriate for this study, according to the recommendations of Byrne (2001) 
and Hair, Anderson, Tatham and Black (1998). The indices used present a more realistic view based on the large sample size, in order to achieve acceptable cut-off values. Table 9 summarises measurements of reliability and validity of key constructs, including Cronbach alpha coefficients.

All Cronbach's (1984) alpha coefficients for leadership, administrative, developmental and informative constructs were found to be above the reliability threshold value of 0.70 (Nunnally, 1978), ranging from 0.702-0.852, which suggests that the construct selected and their corresponding determinants were both reliable and valid for the purpose intended. This means that the four constructs had internal reliability of $0.702,0.705,0.736$ and 0.796 , all $\geq 0.70$ and therefore acceptable in Social Science studies (Price \& Mueller, 1986). However, the Cronbach alphas of the other two constructs - management competency and moderation - were slightly lower, but were retained, with a reliability of 0.640 and 0.667 respectively (Holmes-Smith, 1998). A large number of the items used in the analysis of the six key constructs displayed acceptable levels of reliability and convergent validity of statistical significance to this research.

TABLE 8: Test statistics for the confirmatory factor analysis (CFA) report.

\begin{tabular}{lll}
\hline Confirmatory factors analysis & Results & Results \\
\hline $\begin{array}{l}\text { Model converged normally after 197 } \\
\text { iterations using ML }\end{array}$ & & \\
Minimum function Chi-square & 3102.887 & - \\
Degrees of freedom & 1259 & - \\
$p$-value & 0.0000 & - \\
Chi-square test baseline model & & - \\
Minimum function Chi-square & 7451.859 & - \\
Degrees of freedom & 1378 & - \\
$p$-value & 0.0000 & - \\
Full model versus baseline model & & - \\
Comparative fit index (CFI) & 0.696 statistically & - \\
& significant & \\
Tucker-Lewis index (TLI) & 0.668 statistically & - \\
& significant & \\
Log-likelihood and information criteria & & - \\
Log-likelihood user model (H0) & -17690.299 & - \\
Log-likelihood unrestricted model (H1) & -16138.855 & - \\
Akaike (AIC) & 35724.598 & - \\
Bayesian (BIC) & 36354.029 & - \\
Root mean square error of approximation & & 0.075 \\
(RMSEA) & & \\
RMSEA & - & -000 \\
90 per cent confidence interval & 0.068 & - \\
$p$-value RMSEA <= 0.05 & - & - \\
\hline Standardised root mean square residual (SRMR) & - \\
\hline
\end{tabular}

\section{Trustworthiness}

The data in this study was subject to reliability and validity testing, to ensure compliance with requirements of trustworthiness.

\section{Reliability}

Principal Component Analysis (PCA) was conducted using the 65 variables of the six functional constructs or themes of the study; this was done to test whether the data collected in this study possessed satisfactorily construct reliability and validity, based on the measurement items determined in the pilot study. On the PCA, the key constructs scored as follows: leadership $\geq 0.750$, management competency $\geq 0.780$, administration $\geq 0.760$, development $\geq 0.740$, information $\geq 0.760$, and moderation $\geq 0.740$. These values confirm their reliability and validity for this research.

This was in support of the qualitative results from the interviews and demographic analysis, as alluded to earlier. Most of factors had loadings $\geq 0.70$, and could not be removed from the final analysis. Table 9 summarises the measurements of reliability and validity of key constructs of this study using statistics, including Cronbach alpha coefficients.

\section{Validity}

Validity was addressed by using squared correlations between two constructs with their respective average variance (AVE) extracted, as illustrated in Table 10. In this study, AVE and Cronbach's alpha values for the leadership construct were compared across the construct variables, and alpha values for each item of leadership were found to be higher than the AVE. This result establishes the achievement of discriminant validity criterion for the leadership construct as statistically significant. The comparisons of the other constructs (administration, development, information and management competency) achieved similar results; this verifies the attainment of discriminant validity for all constructs.

\section{Discussion \\ Outline of the results}

The purpose of this research was to remind the leadership and management within organisations that performance

TABLE 9: Alpha coefficients and items for constructs of the study.

\begin{tabular}{|c|c|c|c|c|c|}
\hline Construct & Subscales & Non-fit items & Fit items & Alpha $(\alpha)$ & Fit comment \\
\hline \multirow[t]{2}{*}{ 1. Leadership } & $V_{1}-$ Leadership process & $2=V_{1.3}, V_{1.6}$ & $2=V_{1.1}, V_{8.1}$ & 0.796 & Good \\
\hline & $\mathrm{V}_{2}$-Culture or climate & $2=V_{2.2}, V_{2.5}$ & $1=V_{2.1}$ & 0.736 & Good \\
\hline 2. Administration & $V_{8}-$ Managing resources & $1=V_{2}$ & $5=V_{7.2}, V_{8.3}, V_{8.5}, V_{10.2}, V_{12.4}$ & 0.705 & Good \\
\hline 3. Development & $\mathrm{V}_{4}-$ Potentials or talents & $2=V_{4,3^{\prime}}, V_{4.4}$ & $6=V_{4.1}, V_{6.2^{\prime}}, V_{8.4}, V_{9.2^{2}}, V_{11.2^{\prime}}, V_{11.3}$ & 0.702 & Good \\
\hline 4. Information & $V_{5}-$ Communication & $1=V_{5.4}$ & $2=V_{5.1}, V_{5.2}$ & 0.852 & Good \\
\hline 5. Management competency & $V_{6}-$ Training or appraisals & $2=V_{6.3}, V_{6.5}$ & $4=V_{6.1}, V_{10.3}, V_{10.4}, V_{11.5}$ & 0.677 & Acceptable \\
\hline 6. Moderation & $\mathrm{V}_{7}$ - Expectations & $2=v_{71}, v_{7.5}$ & $1=v_{73}$ & 0.770 & Good \\
\hline
\end{tabular}


appraisal systems, as a tool, were originally designed to focus more on employee development, but gradually the focus has shifted to reward. The modified structural performance appraisal model (MSPAM) framework offers leadership and management a new opportunity to identify and locate the determinant(s) that may be responsible for the appraisal's ineffectiveness and to implement remedial actions. It was the intention of this article to attempt to address this anomaly.

The outcome of this study has been the development of an MSPAM incorporating the six identified constructs and their 12 determinants into an effective framework. In MSPAM, employees' reward and attitudes, identified in the findings of the study as outcomes, have been relocated to the outcome component. It had, however, to be established in the study whether and how effective reward was as a determinant of performance appraisal.

\section{Is reward a determinant of performance appraisal effectiveness?}

Semakula-Katende (2012) identified 12 major drivers or determinants (V) of performance appraisals, which were systematically clustered into six themes or constructs $(\mathrm{T})$. The determinants included:

- Leadership (T1)

- leadership process (V1)

- organisational culture or climate (V2)

- Administrative (T2)

- managing resources (V8)

- reward (V10)

- Development (T3)

- developing potentials and placement of talents (V4)

- aligning them with organisational goals (V3)

- Information (T4)

- communication and MIS (V5)

- Management competency (T5)

- managing appraisals (V6)

- diversity in the workplace (V12)

- acknowledgment of high performers (V4)
- Moderation (T6)

- human motivation (V3)

- human attitudes (V11)

- demographics

In this study it was also found that two factors initially perceived as determinants, reward and attitudes, were actually outcomes of an effective performance appraisal. This was supported by empirical evidence from the statistical analysis of the questionnaire data, and the qualitative findings from the interviews.

The personal interviews included an open-ended item, which afforded respondents an opportunity to share their own opinions on what they thought was the best solution to the EPMDS problem. The majority of them, 78\%, opted for development of a new tool, because the present one was career sensitive and could not be applied broadly without compromising its effectiveness.

Furthermore, two new determinants were identified, namely alignment of goals and acknowledgement of performers.

These factors were also found to have a direct, positive and significant influence on certain factors, specifically reward, attitudes, productivity and teamwork, as outcomes of an effective performance appraisal. This finding was supported by qualitative (interview) and empirical (questionnaire) research findings.

Table 11 provides a summary of statistical analysis of these two factors. Importantly, it was noted that employee attitudes and rewards were not determinants, as earlier postulated, but rather part of the outcome domain of appraisal systems. Both the Cronbach alpha and SCM values of reward and attitudes support their reliability as factors of an effective appraisal system. These variables, however, were identified as outcomes during factor analysis.

\section{Practical implications}

In most of the earlier studies, reward was given more prominence than other drivers, such as leadership

TABLE 10: Comparison of Cronbach's alpha and AVE across leadership construct.

\begin{tabular}{|c|c|c|c|c|c|c|c|c|}
\hline Factor & $V_{1.1}$ & $v_{1.2}$ & $V_{1.3}$ & $\mathrm{~V}_{1.4}$ & $\mathrm{~V}_{1.5}$ & $v_{1.6}$ & $V_{1.7}$ & $\mathrm{~V}_{1.8}$ \\
\hline Alpha & 0.766 & 0.776 & 0.781 & 0.772 & 0.771 & 0.778 & 0.779 & 0.766 \\
\hline Average & 0.758 & 0.705 & 0.687 & 0.601 & 0.717 & 0.706 & 0.713 & 0.657 \\
\hline $\mathrm{V}_{1.1}$ & 1 & - & - & - & - & - & - & - \\
\hline $\mathrm{V}_{1.2}$ & 0.602 & 1 & - & - & - & - & - & - \\
\hline$V_{1.3}$ & 0.388 & 0.315 & 1 & - & - & - & - & - \\
\hline$V_{1.4}$ & 0.419 & 0.292 & 0.428 & 1 & - & - & - & - \\
\hline $\mathrm{V}_{1.6}$ & 0.196 & 0.229 & 0.226 & 0.201 & 0.441 & 1 & - & - \\
\hline$V_{1.7}$ & 0.260 & 0.195 & 0.239 & 0.224 & 0.325 & 0.518 & 1 & - \\
\hline $\mathrm{V}_{1.8}$ & 0.391 & 0.359 & 0.279 & 0.292 & 0.410 & 0.359 & 0.414 & 1 \\
\hline
\end{tabular}

TABLE 11: Density graph of reliability analysis of reward and attitudes.

\begin{tabular}{lllllll}
\hline Variable & Raw alpha & Standard alpha & G6 (SMC) & Average $r$ & Mean & Standard deviation \\
\hline$V_{10}$ Reward & 0.75 & 0.75 & 0.74 & 0.43 & 0.72 \\
$V_{11}$ Attitudes & 0.80 & 0.80 & 0.82 & 0.38 & 2.00 & 2.00 \\
\hline
\end{tabular}

G6 (SMC), Guttman 6 reliability (Squared multiple correlation) 
succession, performance sustainability and development. There was a theoretical gap that this study attempted to address, in order to bring other purposes of appraisal to an equal level with reward. This in turn would improve the effectiveness of performance appraisals and organisations at large. Addressing this gap will hopefully be of value to nonprivate sector organisations and also add to the existing body of knowledge.

The findings have a number of interesting implications for HRM practices. To change people's perception so that they start regarding reward as an outcome will require retraining and re-skilling of key stakeholders. Reward as an outcome ought to be treated as no more important than others, such as leadership succession, performance sustainability, productivity, teamwork, empowerment and commitment.

The number of key determinants remains 12; however, alignment and acknowledgement now replace reward and attitudes, which have been moved to the outcome category. It may be argued that, through addressing those factors and possibly developing a new performance evaluation model built with the incorporation and recognition of those factors in mind, an effective performance appraisal, the MSPAM, has emerged. It is hoped MSPAM will allow organisations to achieve greater success (Semakula-Katende, 2012).

\section{Limitations of the study}

This article presents the evidence of a research effort exposing the performance management experience in public government hospitals, which by implication reflects recent issues in the South African public service. The research findings made a general contribution to the knowledge of how performance appraisals were conducted and the management and employee issues associated with this process in organisations. However, the findings are specifically applicable to public government hospitals and further research to expand the generalisability of the findings is needed.

\section{Conclusion}

The purpose of this study was to address the prominence of reward in performance appraisal. As a determinant, reward is supposed to be treated equally with the other 11 determinants. However, it has been receiving more attention than the others. The evidence presented in this article has established that contrary to the previous perception held by many role players (leaders, managers and employees), reward and attitudes were found to be unintended outcomes of an effective performance appraisal.

This was supported by both qualitative findings from the personal interviews, and empirical evidence generated from statistical analysis of the data from the survey questionnaire. In conclusion, the establishment of reward as an outcome is critical for the planning and implementation of a performance appraisal system. It is equally important that the development of training programmes should address stakeholders' perceptions to enhance performance appraisal effectiveness.

Developers of training and promotion programmes for leaders, managers and employees should include mechanisms to address the aspect of reward and attitudes as outcomes of the performance appraisal.

\section{Acknowledgements Competing interests}

The authors declare that they have no financial or personal relationship(s) that may have inappropriately influenced them in writing this article.

\section{Authors' contributions}

S.M.S-K. (North-West University) collected the data, E.D.S. (Cranefield College) was the project leader and T.G.P. (North-West University) compiled the manuscript.

\section{References}

Amaratunga, D., Baldry D., Sarshar M., \& Newton, R. (2002). 'Quantitative and qualitative research in the built environment: Application of "mixed" research approach'. Work Study, 51, 17-31. http://dx.doi.org/10.1108/00438020210415488

Banks, C.G., \& Murphy, K.R. (1985). Toward narrowing the research-practice gap in performance appraisal. Personnel Psychology, 38, 335-345. http://dx.doi. org/10.1111/j.1744-6570.1985.tb00551.x

Bentler, P.M. (1995). EQS: Structural Equations Program Manual. Encino, CA: Multivariate Software. PMid:8527346

Blanche, M.T., Durrheim, K., \& Painter, D. (2006). Research in Practice: Applied Methods for the Social Sciences. Cape Town: UCT Press.

Boyatzis, R.E. (1982). The competent manager: A model for effective performance. New York: John Wiley and Sons.

Bless, C., \& Higson-Smith, C. (2000). Fundamentals of Social research Methods: An African Perspective. Cape Town: Juta Education (Pty) Ltd.

Byrne, B.M. (2001). Structural Equation Modelling with AMOS - Basic Concepts, Applications and Programming. Mahwah, NJ: Lawrence Erlbaum.

Cameron, R.G., \& Stone, A.B. (2007). Serving the public. A guide for practitioners and students. Pretoria: Van Schaik.

Carroll, G.R., \& Hannan, M.T. (2000). The Demography of Corporations and Industries. Princeton, NJ: Princeton University Press.

Cleveland, J.N., Murphy, K.R., \& Williams, R.E. (1989). Multiple uses of performance appraisal: Prevalence and correlates. Journal of Applied Psychology, 74, 130-135. http://dx.doi.org/10.1037/0021-9010.74.1.130

Collis, J., \& Hussey, R. (2009). Business Research: A Practical guide for undergraduate and post graduate students. Hampshire: Palgrave Macmillan.

Cooper, D.R., \& Schindler, P.S. (2008). Business research Methods. (10th edn.). Boston: McGraw-Hill.

Cronbach, L.J. (1984). Essentials of Psychological Testing. (4th edn.). New York: Harper and Row.

Cropanzano, R., \& Wright, T.A. (2001). When a 'Happy' Worker Is Really A 'Productive' Worker: A Review and Further refinements of the Happy-Productive Worker Thesis. Journal of Consulting Psychology, 53, 180-205.

David, M., and Sutton, C.D. (2004). Social Research: The basics. London: SAGE Publications Ltd.

Davis, J.S. (2001). Approaches to performance appraisal in student affairs. College Student Affairs Journal, 21, 92-100.

Easterby-Smith, M., Thorpe, R. \& Lowe, A. (1994). Management Research: An Introduction. London: Sage Eckes. PMid:7713541

Fisher, C.D., Schoenfeldt, L.F., \& Shaw J.B. (2003). Human Resource Management. (5th edn.). Boston: Houghton Mifflin Company.

Fletcher, C. (1993). Appraisal: An Idea whose time has gone? Institute of Personnel Management, September, 34-37.

Fletcher, B. \& Jones, F. (1993). A Refusal of Karasek's Demand-Discretion Model of Occupational Stress with a Range of Dependent Variables. Journal of Organisational Behaviour, 14, 317-340. http://dx.doi.org/10.1002/job.4030140404

Forsyth, P. (2004). How to Motivate People: Learn the Key Skills; Get Best Results; and develop, Appraise, Empower. London: Kogan Page Limited. 
Freeman, J. (2002). How to improve the effectiveness of performance management and appraisal by overcoming the root cause of the problem. The HRM Guide and appraisal by overcoming the root cause of the problem. The HRM Guide
Network. Retrieved December 05, 2002, from www.hrmguide.com/ performance.

Free State Provincial Government (FSPG). (2003). Policy Framework: Performance and development management Systems for levels 2-12. Bloemfontein: Provincial Government Printers.

Free State Provincial Government (FSPG). (2007). Human Resource Management Circular No. 15. Pretoria: Government Printers.

Free State Provincial Government (FSPG). (2008). Human Resource Management, Business Plan. Pretoria: Government Printers.

Gillen, T. (2007). Performance management and appraisal. (2nd edn.). CIPD toolkit. London: Chartered Institute of Personnel and Development.

Goodge, P. (2005). How to link 360 degree feedback and appraisal. People Management, 11, 46-47.

Hair, J.F.J., Anderson, R.E., Tatham, R.L., \& Black, W.C. (1998). Multivariate Dato Analysis. New York: Maxwell Macmillan International.

Hill, C.W.L., \& Jones, G.R. (2001). Strategic Management. Houghton: Mifflin.

Holmes-Smith, P. (1998). Introduction to Structural Equation Modelling Using LISREL and AMOS. School Research, Evaluation, and Measurement Services. Brisbane: Qld.

Hutchinson, S., \& Purcell, J. (2003). Bringing policies to life: The vital role of front line managers in people management: Executive briefing. London: Chartered Institute of Personnel and Development.

Ilgen, D.R., Fisher, C.D., \& Taylor, S.M. (1979). Consequences of individual feedback on behavior in organisations. Journal of Applied Psychology, 64, 349-371. http:// dx.doi.org/10.1037/0021-9010.64.4.349

Karl, K.A., \& Wexley, K.N. (1989). Patterns of performance and rating frequency: Influence on the assessment of performance. Journal of Management, 15, 5-20. http://dx.doi.org/10.1177/014920638901500102

Kaplan, R.S., \& Norton, D.P. (2005). The Balanced Scorecard: Measures That Drive Performance. Harvard Business Review, 83, 174-180.

Margulies, J. (2004). 'Performance Appraisals'. Retrieved January 18, 2009, from http://www.bnabooks.com/ababna/eeo/2004/eeo55.pdf

McEvoy, G.M. (1990). Public sector managers' reactions to appraisals by subordinates. Public Personnel Management, 19, 201-212.

Neely, A., Adams, C., \& Kennerley, M. (2002). The Performance Prism: The Scorecard for Measuring and Managing Business Success. London: Business Success, Financial Times.
North-West University. (2007). Research and Ethical Guidelines. Mafikeng: NorthWest University Press.

Nunnally, J.C. (1978). Psychometric Theory. (2nd edn.). New York: McGraw-Hill.

Pfeffer, J., \& Veiga, J.F. (1999). Putting People First for Organisational Success. Academy of Management Executive, 13, 37-48.

Price, J.P., \& Mueller, C.W. (1986). Handbook of Organizational Measurement. Marshfield, MA: Pitman.

Quinn, R.E. (1988). Beyond Rational Management: Mastering the Paradoxes and Competing Demands of High Performance. San Francisco: Jossey-Bass.

Quinn, R.E., Faerman, S.R., Thompson, M.P., and McGrath, M.R. (1996). Becoming a Master Manager: A Competency Framework. New York: John Wiley.

Renton, M. (2000). Increase productivity through effective performance management. People Dynamics, 18, 41 .

Republic of South Africa. (1994). Public Service Act 103. Pretoria: Government Printer.

Rudman, R. (2004). Performance Planning and Review: Making Employee Appraisals Work. (2nd edn.). Australia: Allen and Unwin. PMCid:PMC2047329

Sangweni, S.S. (2003). Performance Management as a leadership and management tool. Service Delivery Review, 2, 20-23.

Saunders, M., Lewis P., \& Thornhill, A. (2007). Research Methods for Business Students. (4th edn.). Englewood Cliffs, NJ: Prentice Hall.

Semakula-Katende, S.M. (2012). An Evaluation of Performance Appraisal and Management in Ten Institutions of the Free State Provincial Government. Mafikeng: North-West University Press.

Tucker, M.L., McCarthy, M.A., \& Benton, D.A. (2002). The Human Challenge: Managing Yourself and Others in Organisations. New Jersey: Prentice Hall.

Ulrich, D. (1997). Human Resources Champions. Cambridge: Harvard Business Schoo Press.

Ulrich D., Smallwood, N., \& Sweetman, K. (2008). The Leadership Code: Five Rules to Lead By. Boston: Harvard Business Press.

West, M., Arnold, J., Corbett, M., \& Fletcher, B. (1992). Understanding About Behaviour at Work. Journal of Organisational Psychology, 65, 1-3. http://dx.doi. org/10.1111/j.2044-8325.1992.tb00479.x

Winberg, C. (1997). Learning How To Research and Evaluate. Cape Town: Juta. PMCid:PMC508199

Winston, R.B., \& Creamer D.G. (1997). Improving staffing practices in student affairs. San Francisco: Jossey-Bass.

Wolff, C. (2005). Appraisals: Not living up to expectations. IRS Employment Review, 828, 9-15. 